\title{
DRUG UTILIZATION PATTERN AND PHARMACOECONOMIC ANALYSIS OF ANTIHYPERTENSIVE DRUGS PRESCRIBED IN SECONDARY CARE HOSPITAL IN GUJARAT, INDIA
}

\author{
NILAY D SOLANKI ${ }^{1 *}$, PRATIK PATEL ${ }^{2}$ \\ ${ }^{1}$ Assistant Professor, Department of Pharmacology, Ramanbhai Patel College of Pharmacy, CHARUSAT, Petlad, Anand, Changa - 388 421, \\ Gujarat, India. ${ }^{2}$ M.Pharm (Clinical Pharmacy), Ramanbhai Patel College of Pharmacy, CHARUSAT, Petlad, Anand, Changa - 388421, Gujarat, \\ India. Email: nilaysolanki.ph@charusat.ac.in \\ Received: 05 October 2016, Revised and Accepted: 23 November 2016
}

ABSTRACT

Objective: Hypertension is the most common condition seen in primary care and leads to myocardial infarction, stroke, renal failure, and death if not detected early and treated appropriately. A large number of antihypertensive drugs alone or in various combinations are available, and physicians need to choose most appropriate drug for a particular patient. Pharmacoeconomic and drug utilization studies at regular intervals help physicians to prescribed rational drugs with high efficacy along with minimal cost.

Methods: The prospective observational study was conducted at Seth H. J. Mahagujarat Hospital from July to December 2013 . 250 hypertensive patients, attending medicine outpatient department were included for drug utilization study and 100 hypertensive patients, attending in patients department were included for pharmacoeconomics analysis during the study period.

Result: The most frequently prescribed antihypertensive drug as monotherapy, as combination therapy and in fixed dose combinations was calcium channel blocker (Amlodipine). Generic drugs showed same efficacy as brand drug, but both drugs were significantly differed in the prize. Among 100 inpatients admitted for the hypertensive condition in general ward total of direct medical cost was $65.19 \%$ and total of indirect medical cost was $34.81 \%$. $\beta$-blocker and diuretics were the most effective therapy which is followed by the clonidine, envas (Enalapril), and then, amlodipine.

Conclusion: We concluded from this study that use of $\beta$-blockers and diuretics were most cost-effective for the hypertensive patients in this study.

Keywords: Antihypertensive drugs, Drug utilization study, Pharmacoeconomics analysis.

(C) 2017 The Authors. Published by Innovare Academic Sciences Pvt Ltd. This is an open access article under the CC BY license (http://creativecommons. org/licenses/by/4. 0/) DOI: http://dx.doi.org/10.22159/ajpcr.2017.v10i3.15537

\section{INTRODUCTION}

Hypertension (HTN) is considered as silent killer. It is one of the most significant risk factors for cardiovascular (CV) morbidity and mortality resulting from target organ damage to blood vessels of the heart, brain, kidney, and eyes [1]. Worldwide, raised blood pressure is estimated to cause 7.5 million deaths, about $12.8 \%$ of the total of all deaths. This accounts for 57 million disability adjusted life years (DALYS) or $3.7 \%$ of total DALYS [2]. Globally CV disease accounts for approximately 17 million deaths a year, nearly one-third of the total [3], of these complications of HTN account for 9.4 million deaths worldwide every year [4]. Premature death, disability, personal and family disruption, loss of income, and health-care expenditure due to HTN, take a toll on families, communities, and national finances. In low- and middle-income countries many people do not seek treatment for HTN because it is prohibitively expensive [5]. Over the period 2011-2025, the cumulative lost output in low- and middle-income countries associated with noncommunicable diseases is projected to be US\$ 7.28 trillion [6]. The annual loss of approximately US\$ 500 billion due to major noncommunicable diseases amounts to approximately $4 \%$ of gross domestic product for low- and middleincome countries. CV disease including HTN accounts for nearly half of the cost [7]. Blood pressure drugs work in several ways, such as removing excess salt and fluid from the body, slowing the heartbeat or relaxing and widening the blood vessels. A wide range of antihypertensive drugs belonging to different pharmacological classes is available. Choice of drugs for a particular patient changes because of factors such as efficacy, side effects, cost, and development of newer drugs. Hence, it is necessary to survey prescription patterns as a component of medical audit for monitoring, evaluation, and necessary modifications in prescribing practices to achieve rational and cost-effective medical care.
The World Health Organization addressed drug utilization as the marketing, distribution, prescription and use of drugs in society, considering its consequences, either medical, social, and economic. The main goal of drug utilization research is to assist the rationale use of drugs in populations. With the knowledge on how drugs are being prescribed and used, a discussion on rational drugs use and suggestions on measures to improve prescribing habits should be more efficiently. Descriptive studies are part of drug utilization research and their main target is to describe variations and trends in the extend, costs, and quality of drug use among individuals and populations [8]. Drug utilization research not only can profile the discrepancy that exists between true need and therapeutic practice but also a tool to correct it. If it is unquestionable the importance of promoting compliance on prescribed medicines, it is not of less importance, to avoid overuse of drugs, which may be responsible for an increase in adverse events, iatrogenic diseases, and unnecessary costs. Since drug utilization studies are designed only to provide the existing distribution of variables, without any regard for causality, external validity of such studies is limited [9].

Joint National Committee guidelines recommend diuretics as the first choice in hypertensive patients with no comorbidities [10]. However, differences still exist between these guidelines and the initial drug of choice in clinical practice [11]. It is estimated that nearly $\$ 60$ billion is spent on managing HTN and its complications annually in the United States, yet only $34 \%$ of the patients treated with antihypertensive medications reach desired blood pressure goals $[10,12]$. Recent studies have stated that much of this increase in cost is attributable to the introduction of new and generally more costly brand name drugs that replace older and less expensive medications [13]. 
Pharmacoeconomics consists of analysis and evaluation of outcomes (clinical, economic, or humanistic), cost consequences, and cost comparison. Pharmacoeconomic evaluations can be applied to assess the value of treatments, to compare the medical cost and health outcomes associated with new therapies/medicines to the cost and to determine the outcome of the existing alternative treatment. Currently European countries are making the maximum use of pharmacoeconomic data for reimbursement and other financial decisions, and most have officially introduced pharmacoeconomics guidelines in their countries. Australia in comparison with European countries has a relatively well-developed pharmacoeconomic structure. Countries in the North American continent, South American continent, and South Africa have introduced the concept of pharmacoeconomics and outcomes research data lately. Countries in Asia such as China, Hong Kong, Japan, Korea, and Singapore have a well-developed pharmacoeconomics and outcomes research structure [14]. In India, full proof system yet to be developed, where the majority of patients are below the poverty line and high cost of treatment is main reason for nonadherence to the treatment. This study was designed to analyze the drug utilization patterns and pharmacoeconomic analysis of antihypertensive drugs prescribed to hypertensive patients.

\section{METHODS}

The prospective observational study was conducted at Seth $\mathrm{H} \mathrm{J}$ Mahagujarat Hospital during the period of July 2013 to December 2013. Ethical approval was obtained from the Institutional Ethics Committee of Rathi Hospital, Ahmedabad. Beer's criteria were used to analyze proportion distribution compare with standard guideline.

\begin{tabular}{lll}
\hline Study & Inclusion criteria & $\begin{array}{l}\text { Exclusion } \\
\text { criteria }\end{array}$ \\
\hline $\begin{array}{l}\text { Drug utilization } \\
\text { pattern }\end{array}$ & $\begin{array}{l}\text { Patient treated with at least } \\
\text { one antihypertensive drug } \\
\text { Patients attending }\end{array}$ & $\begin{array}{l}\text { Mentally retarded } \\
\text { and unconscious } \\
\text { patients }\end{array}$ \\
outpatient department & \\
Pharmacoeconomic & $\begin{array}{l}\text { Patients who were } \\
\text { analysis }\end{array}$ & $\begin{array}{l}\text { Mentally retarded } \\
\text { antihypertensive treatment patients } \\
\text { in general ward } \\
\end{array}$ \\
& $\begin{array}{l}\text { Patient treated with at least } \\
\text { one antihypertensive drug }\end{array}$ \\
\hline
\end{tabular}

\section{Sample size}

250 hypertensive patients, attending medicine outpatient department were included for drug utilization study and 100 hypertensive patients, attending in patients department were included for pharmacoeconomics analysis during the study period (Fig. 1).

\section{Data analysis}

The proportion of patients using different classes of antihypertensive was calculated and analyzed using the M.S. Excel. Mean \pm standard error of mean is utilized for statistical analysis. All the costs including direct costs and indirect costs were collected in the per forma, which includes: Cost of medication, cost of medical consultation, cost of laboratory tests, cost of transport and meal, indirect cost due to loss of productivity. The economic outcome, cost minimization analysis, cost of illness, and costeffectiveness analysis measured as QALY - quality adjusted life years.

\section{RESULT AND DISCUSSION}

In this study, 136 patients (54.4\%) were males and 114 (45.6\%) were females indicating $8.8 \%$ higher prevalence of HTN in male population. As shown in Table 1, the prevalence of HTN increases with age. Hence, age is one of the main factors for HTN. Our study showed that out of 250, 51 patients have hereditary condition of HTN. Hence, family history of elevated blood pressure is one of the strongest risk factors for future development of HTN in individuals. Among 250 patients, 112 patients have comorbid condition along with HTN. In our study, finding the majority of the patients 66 (57.89\%) have diabetes mellitus (DM) followed by myocardial ischemia 26 (22.80\%), thyroid complications 16 (14.03\%), asthma 04 (3.50\%), chronic obstructive pulmonary disease (COPD 1) $(0.87 \%)$, and migraine $1(0.87)$. The most frequently prescribed antihypertensive drug group was angiotensin 2 receptor blockers for patients who have comorbidity of DM (51.5\%). Distribution of hypertensive patient according to age, duration of HTN, body mass index (BMI), systolic blood pressure, and diastolic blood pressure were showed in Table 1 . The age difference between two gender groups $(\mathrm{p} \leq 0.05)$ was statistically significant.

In the Table 2, showed that BMI of patients fall in normal range (49.6\%). Although obese patient was more found in case of female compared to male patients and the mean BMI of the patients in our study were approximately $23.95 \mathrm{~kg} / \mathrm{m}^{2}$ which imply that the patients are normal range. While in one of the clinical work showed average BMI 27.16 \pm 2.85 in male patients and $26.40 \pm 3.65$ in female patients during course of antidiabetic therapy, which implies that the patients were overweight (BMI $\geq 25 \mathrm{~kg} / \mathrm{m}^{2}$ ) and were on the borderline of becoming obese (BMI $\geq 30 \mathrm{~kg} / \mathrm{m}^{2}$ ), which in itself is a well-recognized significant risk factor for DM [15] and HTN. In most of the studies, being overweight was associated with a 2 -fold to 6 -fold increase in the risk of developing HTN. Framingham study suggests that $10 \%$ increase in weight a rise of $6.5 \mathrm{~mm} \mathrm{Hg}$ in systolic pressure [16]. It also suggested that $65 \%$ of the risk for HTN in women and $78 \%$ in men can be related to obesity. The study done in Jaipur urban (both sexes) and rural studies (only males) [17], the Haryana rural study [18], the Chennai urban population study [19] as well as the Bombay executive study [20] have all shown a higher weight and BMI among hypertensive groups.

Distribution of drug in hypertensive patient - Monotherapy

A total of 187 (74.8\%) patients received monotherapy. This study revealed that calcium channel blockers were the drugs of choice for hypertensive patients because it is prescribed to $54(28.87 \%)$ patient

Table 1: Demographical and clinical parameters of hypertensive patients

\begin{tabular}{lllll}
\hline $\begin{array}{l}\text { Demographic } \\
\text { characteristics }\end{array}$ & Gender & $\begin{array}{l}\text { Number } \\
\text { of } \\
\text { patients }\end{array}$ & Mean \pm SEM & p value \\
& & & \\
\hline Age (years) & Male & 136 & $61.448 \pm 0.889$ & 0.499 \\
& Female & 114 & $56.543 \pm 0.880$ & \\
& Total & 250 & $59.212 \pm 0.684$ & \\
DHTN (months) & Male & 136 & $49.65 \pm 4.8506$ & 1.601 \\
& Female & 114 & $42.798 \pm 4.937$ & \\
& Total & 250 & $46.528 \pm 3.4685$ & \\
BMI $\left(\mathrm{kg} / \mathrm{m}^{2}\right)$ & Male & 136 & $23.305 \pm 0.436$ & 1.764 \\
& Female & 114 & $24.735 \pm 0.5535$ & \\
& Total & 250 & $23.95 \pm 0.3487$ & \\
SBP $(\mathrm{mm}$ of Hg) & Male & 136 & $143.23 \pm 1.616$ & 0.499 \\
& Female & 114 & $149.34 \pm 1.969$ & \\
& Total & 250 & $146.02 \pm 1.269$ & \\
DBP $(\mathrm{mm}$ of Hg) & Male & 136 & $84.338 \pm 0.743$ & 0.024 \\
& Female & 114 & $85.394 \pm 0.758$ & \\
& Total & 250 & $84.82 \pm 0.5319$ & \\
\hline
\end{tabular}

HTN: Hypertension, SBP: Systolic blood pressure, BMI: Body mass index, DBP: Diastolic blood pressure

Table 2: Classification of BMI in hypertensive patients

\begin{tabular}{lllll}
\hline Classification & BMI (kg/m2) & Male (\%) & Female (\%) & Total (\%) \\
\hline Underweight & $<18.50$ & $22(16.17)$ & $07(06.14)$ & $29(11.60)$ \\
Normal range & $18.50-24.99$ & $67(49.26)$ & $57(50.00)$ & $124(49.60)$ \\
Overweight & $25.00-29.99$ & $35(25.73)$ & $33(28.94)$ & $68(27.2)$ \\
Obese & $\geq 30.00$ & $12(08.82)$ & $17(14.91)$ & $29(11.6)$ \\
Total & & $136(100.0)$ & $114(100.0)$ & $250(100.0)$ \\
\hline
\end{tabular}

BMI: Body mass index 
of HTN as a single drug therapy, followed by the fixed dose combination (FDC) of $\beta$-blockers with amlodipine 42 (22.45\%), $\beta$-blockers 37 (19.78), angiotensin 2 receptor blocker 23 (12.29\%), diuretics 9 (4.81\%), angiotensin converting enzyme inhibitors 9 (4.81\%), centrally acting drug $2(1.06 \%)$, and others. Diuretics are generally recommended as first-line therapy for treatment of HTN (JNC V; JNC VI) (Fig. 2). Utilization of diuretics in this study was $7.44 \%$ as monotherapy. Lesser use of diuretics in this study may be due to adverse effect of diuretics on glucose homeostasis and lipid profile [21]. In an Indian study, $40 \%$ of patients received monotherapy [22]. Tiwari et al. study also support this result of high use of calcium channel blockers as monotherapy (Fig. 2).

\section{Distribution of drugs in hypertensive patients}

A total of 49 (19.6\%) patients received dual therapy. Among them, 15 patients received $\mathrm{Ca}^{2+}$ channel blocker along with other drugs such as atenolol, revolol, enalapril, telmisartan, and clonidine, (telmisartan +atenolol) (losartan + hydrochlorthiazide). Other 14 patients received combination of FDCs $\left(\mathrm{Ca}^{++}\right.$channel blocker $+\beta$-blocker) along with other drugs such as enalapril, clonidine, losartan, telmisartan, while 9 patients received combination of diuretics (furosemide) along with other drugs such as amlodipine, atenolol, and telmisartan. The remaining 11 patients prescribed $\beta$-blocker along with telmisartan, losartan, enalapril, clonidine, and amlodipine (Table 3). Only one patient prescribed the quadruple therapy with combination of amlodipine, hydrochlorothiazide, clonidine, and metoprolol.

\section{Associated comorbidity with HTN}

In our study, finding the majority of the patients 66 (57.89\%) have DM followed by myocardial ischemia $26(22.80 \%)$, thyroid disease $16(14.03 \%)$, asthma $04(3.50 \%)$, COPD 1 (0.87\%), and migraine 1 (0.87). A study carried out by Olusegun Adesola found 43 hypertensive patients $(n=240)$ had coexisting DM [23]. In one clinical study, found that the most common comorbidity in HTN was DM, 98 (38.4\%); followed by dyslipidemia in 50 (19.6\%), bronchial asthma in 28 (11.0\%), and renal diseases in 12 (4.7\%) [24]. Another study showed that the highest comorbid condition found with HTN were diabetes (13\%), followed by hyperlipidemia (7.5\%), renal disease, and obesity (6.5\% each). Peptic ulcer disease and stroke (4\% each) and congestive cardiac failure (3.5\%) [25].

\section{Pharmacoeconomic study}

Cost minimization

There is no significant difference between efficacies of these two drugs (branded vs. generic drugs) ( $p>0.05$ ), these drugs do significantly differ in the prizes. Hence, prescribing generic as their cost is low compared to branded products which is a good option for trust based hospital and also beneficial for rural people (Table 4).

\section{Cost of illness}

Total of direct medical costs among 100 inpatients admitted due to hypertensive crises in general ward was $65.19 \%$, among them, cost of health personnel (physician and nursing charges) constituted $25.43 \%$, cost of medication constituted $28.53 \%$, and laboratory cost constituted $11.24 \%$ of from the direct medical costs for the hypertensive condition.

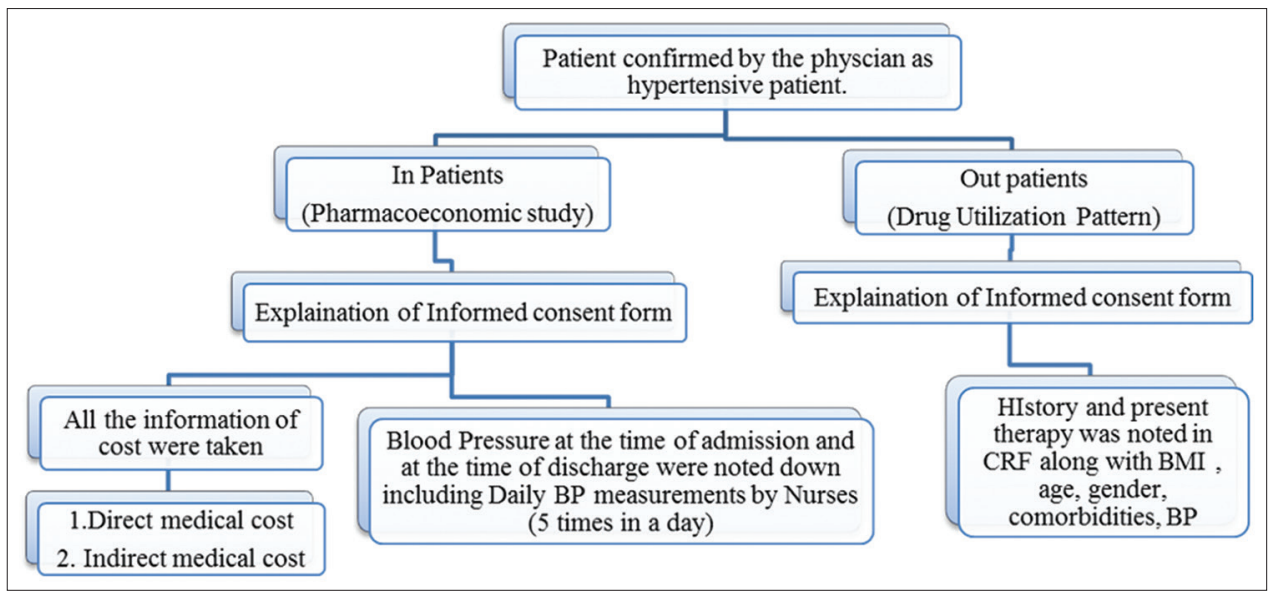

Fig. 1: Overview of methodology (CRF - Case record form, BMI - Body mass index, BP - Blood pressure)

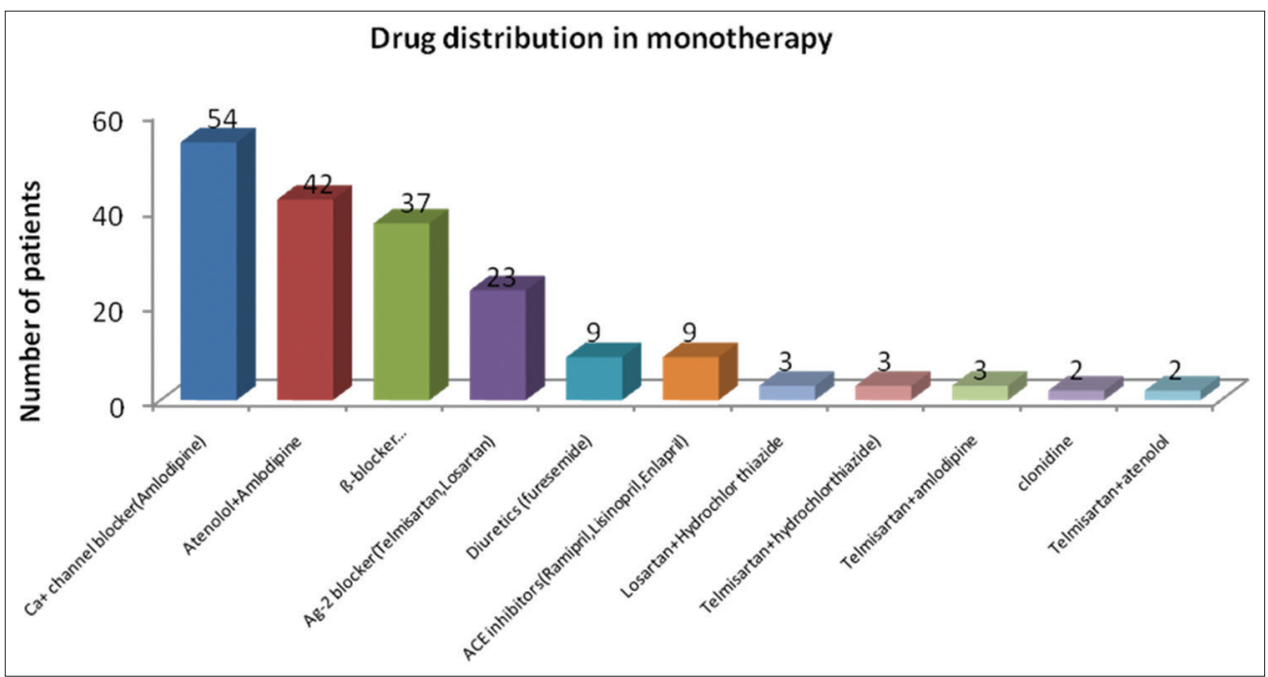

Fig. 2: Drug utilization of antihypertensive drug as a monotherapy 
Table 3: Combination drug therapy in hypertensive patients

\begin{tabular}{llllll}
\hline First line of drug & $\begin{array}{l}\text { Second drug } \\
\text { prescribed }\end{array}$ & Number of patients & Combination drugs & $\begin{array}{l}\text { Antihypertensive } \\
\text { class of drug }\end{array}$ & Number of patients \\
\hline Ca++channel blocker (s) & Atenolol & 47 & -blockers+Ca+channel & Losartan & 4 \\
& Revolol & 2 & blocker & Telmisartan & 4 \\
& Enalapril & 4 & & Enalapril & 5 \\
& Telmisartan & 2 & & Furosemidine & 5 \\
\multirow{5}{*}{ Diuretic } & Clonidine & 2 & Ca+2 channel & Losartan & 1 \\
& Amlodipine & 3 & blockers+diuretics & Telmisartan & 1 \\
\multirow{3}{*}{$\beta$-blocker (s) } & Atenolol & 1 & Revolol+enalapril & Furosemide & 1 \\
& Telmisartan & 7 & Amlodipine+furosemide & Clonidine & 1 \\
& Losartan & 2 & Total triple therapy & & 29 \\
Total & Telmisartan & 4 & & & \\
\hline
\end{tabular}

Table 4: Analysis of cost minimization

\begin{tabular}{|c|c|c|c|c|c|c|}
\hline Brand name & Cost/tablet (Rs.) & Cost/30 tablet (Rs.) & $\begin{array}{l}\text { Suggested } \\
\text { generic drug }\end{array}$ & Cost/tablet (Rs.) & Cost/30 tablet (Rs.) & $\begin{array}{l}\text { Benefit of } \\
\text { generic } \\
\text { drug (Rs.) }\end{array}$ \\
\hline Amtas (Intas) & 3.18 & 97.2 & UDP (Unison) & 0.6 & 18 & 77.5 \\
\hline Amlodac (Zydus) & 3.24 & 95.5 & & & & 79.2 \\
\hline Cupine at & 2.89 & 86.7 & UDP at (Unison) & 0.927 & 27.83 & 58.86 \\
\hline
\end{tabular}

Table 5: Cost-effectiveness ratio of different antihypertensive drugs

\begin{tabular}{|c|c|c|c|c|}
\hline S.No & Class of antihypertensive drug & Average of total cost for treatment (Rupees) (C) & QALYs & Cost effectiveness $=\mathrm{C} / \mathrm{QALYs}$ \\
\hline 1 & Envas (enalapril) & 3478 & 0.6749 & 5153.38 \\
\hline 2 & Amlodac (amlodipine) & 3551 & 0.6496 & 5467.36 \\
\hline 3 & Cupine-AT (amlodipine+atenolol) & 3728 & 0.6071 & 6140 \\
\hline 4 & Arkamin (clonidine) & 3263 & 0.6492 & 5025.30 \\
\hline 5 & Betaloc (atenolol) & 3630 & 0.7410 & 4894.57 \\
\hline 6 & Amifrue (furosemide) & 3560 & 0.7499 & 4746 \\
\hline 7 & Losartan & 3925 & 0.606 & 5902 \\
\hline
\end{tabular}

QALYs: Quality adjusted life year

Total of indirect medical costs among 100 inpatients admitted for the hypertensive condition in general ward is $34.81 \%$, among them, cost of loss of productivity (missed earning days) constituted 15.29, cost of transportation, and meal are $19.51 \%$ from the indirect medical costs for hypertensive condition.

\section{Cost-effectiveness analysis}

Diuretics and $\beta$-blockers were the most effective therapy which is followed by the clonidine, enalapril, amlodipine, and other class of drugs. The cost-effectiveness studies alter with comorbidities associated with HTN. In this study, the majority of patients associated with $\mathrm{CV}$ disorders so $\beta$-blocker is most cost-effective drug in this study.

Cost effectiveness is dependent on QALYs. Higher the QALYs better the cost effectiveness which directly affects the total cost and ultimately benefited to patients and overall economic burden of therapy is reduced (Table 5).

\section{CONCLUSION}

The most frequently prescribed antihypertensive drug group was calcium channel blocker as monotherapy, though diuretics are the first line choice of drug therapy for the HTN. Lesser use of diuretics in this study may be due to adverse effect of diuretics on glucose homeostasis and lipid profile. The most prevalent combination of drugs prescribed were calcium channel blockers $+\beta$-blockers as dual, triple, and as FDCs.

In pharmacoeconomics study, we concluded that it is beneficial for developing countries where the majority of people below the poverty line and nonadherence to therapy are observed only because of the high cost of the treatment. By the cost minimization, we concluded that use of generic drug significantly affects the cost of medication without change in the safety and efficacy. In cost of illness, we concluded that indirect cost was invisible to the patient but it covers near to $30 \%$ of the total cost, by proper knowledge of pharmacoeconomics we can minimize the indirect cost of treatment by minimizing the duration of stay depending on disease condition. Finally, we concluded from this study that use of $\beta$-blockers and diuretics were most cost-effective for the hypertensive patients in this study.

\section{REFERENCES}

1. Saseen JJ. Essential hypertension. In: Kode-kimble MA, editors. Applied Therapeutics: The Clinical Use of Drugs. $9^{\text {th }}$ ed. USA: Lippincott Williams and Wilkins; 2009. p. 314.

2. Available from: http://www.who.int/gho/ncd/risk_factors/blood pressure prevalence text/en. [Last downloaded on 2016 Apr 16].

3. Causes of Death. Geneva: World Health Organization; 2008. Available from: http://www.who.int/healthinfo/global burden disease/ cod 2008 sources methods.pdf.

4. Lim SS, Vos T, Flaxman AD, Danaei G, Shibuya K, Adair-Rohani H, et al. A comparative risk assessment of burden of disease and injury attributable to 67 risk factors and risk factor clusters in 21 regions, 1990-2010: A systematic analysis for the Global Burden of Disease Study 2010. Lancet 2012;380(9859):2224-60.

5. World Health Organization. Impact of Out-of-pocket Payments for Treatment of Non-Communicable Diseases in developing Countries: A Review of Literature WHO Discussion Paper 02/2011. Geneva: World Health Organization; 2011.

6. World Health Organization and World Economic Forum. From Burden 
to "Best Buys": Reducing the Economic Impact of Non-Communicable Diseases in Low-and Middle-Income Countries. Geneva: World Health Organization and World Economic Forum; 2011. Available from: http:// www.who.int/nmh/publications/best buys summary.

7. World Economic Forum and the Harvard School of Public Health. The Global Economic Burden of Non-communicable Diseases. Geneva: World Economic Forum and the Harvard School of Public Health; 2011.

8. World Health Organization. Introduction to drug utilization research. WHO International Working Group for Drug Statistics Methodology, WHO Collaborating Centre for Drug Statistics Methodology, and WHO Collaborating Centre for Drug Utilization Research and Clinical Pharmacological Services. Oslo, Norway: World Health Organization; 2003.

9. Figueiras A, Caamano F, Otero JG. Methodology of drug utilization studies in primary health care. Gac Sanit 2000;14:7-19.

10. Chobanian AV, Bakris GL, Black HR. National heart, lung, and blood institute Joint National Committee on Prevention, Detection, Evaluation, and Treatment of High Blood Pressure; National High Blood Pressure Education Program Coordinating Committee. The Seventh Report of the Joint National Committee on Prevention, Detection, Evaluation, and Treatment of High Blood Pressure: The JNC 7 Report. JAMA 2003;289(19):2560-72.

11. Ganguli A, Hong SH. Profiles of Initial Drug Therapies Among Newly Diagnosed Hypertensive Patients with No Compelling Indications. Poster (PCV53) Presented At: International Society for Pharmacoeconomics and Outcomes Research $12^{\text {th }}$ Annual International Meeting, May; 2007.

12. After the diagnosis: Adherence and persistence with hypertension therapy. Am J Manag Care 2005;11 13 Suppl: S395-9.

13. Lichtenberg FR. Are the benefits of newer drugs worth their cost? Evidence from the 1996 MEPS. Health Aff (Millwood) 2001;20(5):241-51

14. Available from: http://www.interlinkconsultancy.com/pdfs/ whitepapers/pharmacoeconomics key to affordable medicines.pdf. [Last downloaded on 2016 Apr 22].
15. Acharya KG, Shah KN, Solanki ND, Rana DA. Evaluation of antidiabetic prescriptions, cost and adherence to treatment guidelines: A prospective, cross-sectional study at a tertiary care teaching hospital. J Basic Clin Pharm 2013;4(4):82-7.

16. Garrison RJ, Kannel WB, Stokes J $3^{\text {rd }}$, Castelli WP. Incidence and precursors of hypertension in young adults: The Framingham Offspring Study. Prev Med 1987;16(2):235-51

17. Gupta R, Guptha S, Gupta VP, Prakash H. Prevalence and determinants of hypertension in the urban population of Jaipur in western India. J Hypertens 1995;13(10):1193-200

18. Malhotra P, Kumari S, Kumar R, Jain S, Sharma BK. Prevalence and determinants of hypertension in an un-industrialised rural population of North India. J Hum Hypertens 1999;13(7):467-72.

19. Deepa R, Shanthirani CS, Pradeepa R, Mohan V. Is the 'rule of halves' in hypertension still valid?--Evidence from the Chennai Urban Population Study. J Assoc Physicians India 2003;51:153-7.

20. Anand MP. Prevalence of hypertension amongst Mumbai executives. J Assoc Physicians India 2000;48(12):1200-1.

21. Dopa M. Pattern of drug use in hypertension in a tertiary hospital: A cross sectional study in the in-patient wards. Indian J Pharmacol 2001;33:456-7.

22. Chalmers J, MacMahon S, Mancia G, Whitworth J, Beilin L, Hansson L, et al. 1999 World Health Organization-International Society of Hypertension Guidelines for the management of hypertension. Guidelines sub-committee of the World Health Organization. Clin Exp Hypertens 1999;21(5-6):1009-60.

23. Busari OA, Olanrewaju TO, Desalu OO, Opadijo OG, Jimoh AK, Agboola SM, et al. Impact of patients' knowledge, attitude and practices on hypertension on compliance with antihypertensive drugs in a resource-poor setting. TAF Prev Med Bull 2010;9(2):87-92.

24. Al-Tuwijri AA, Al-Rukban MO. Hypertension control and comorbidities in primary health care centers in Riyadh. Ann Saudi Med 2006;26(4):266-71.

25. Tamuno I, Fadare J. Drug treatment for hypertension in a tertiary health care facility in Northern Nigerian. Int J Pharm 2011;2(2):104-9. 